\title{
Uso de anfetamínicos por motoristas profissionais brasileiros: aspectos gerais
}

\section{Amphetamine use by truck drivers in Brazil: general aspects}

Vilma LEYTON¹,2, Débora Gonçalves de CARVALHO², Maria das Graças Silva de JESUS², Daniel Romero MUÑOZ

LEYTON, V.; CARVALHO, D. G. DE; JESUS, M. G. S. DE; MUÑOZ, D.R. Uso de anfetamínicos por motoristas profissionais brasileiros: aspectos gerais. Saúde, Ética \& Justiça, 5/7(1-2):32-6, 2000-2002.

Resumo: Vários estudos mostram a relação do uso de anfetamínicos e a ocorrência de acidentes de transito. Os motoristas profissionais de transporte rodoviário de cargas no Brasil fazem uso indiscriminado de medicamentos à base dessas substâncias, conhecidos popularmente como "rebites", objetivando aumentar o tempo de vigília para cumprir prazos e horários estabelecidos pelas empresas contratantes. Este trabalho busca contribuir com informações a respeito dos anfetamínicos, bem como as implicações do seu uso por condutores de veículos, sobretudo os caminhoneiros.

Unitermos: Anfetaminas/toxicidade. Anfetaminas/efeitos adversos. Condução de veículo/estatística \& dados numéricos.

\section{Introdução}

O uso de substâncias psicoativas por motoristas profissionais brasileiros, principalmente os que trabalham no transporte de carga é amplamente difundido no Brasil. Para diminuir o sono e o cansaço nas longas viagens, muitos motoristas têm usado, indiscriminadamente, medicamentos estimulantes popularmente conhecidos como "rebites", com o propósito de aumentar o tempo de vigília. Os fármacos mais utilizados são estimulantes sintéticos como os anfetamínicos, usualmente encontrados em medicamentos anorexígenos utilizados nos regimes de emagrecimento. Esses medicamentos muitas vezes são associados à ingestão de outras substâncias psicoativas, afetando a saúde dos caminhoneiros e prejudicando, de maneira significativa, a habilidade do motorista de dirigir aumentando o risco da ocorrência de acidentes ${ }^{6,21}$.

A relação entre o uso de substâncias psicoativas por motoristas e a ocorrência de acidentes de trânsito tem sido demonstrada em diversos países ${ }^{3,9,16}$. No Brasil, no entanto, os dados a respeito do uso dessas substâncias pelos condutores são muito escassos. Um dos poucos estudos foi realizado por Silva et al. ${ }^{22}$ com 728 motoristas e mostrou que $4,8 \%$

\footnotetext{
1. Profa. Dra. da Disciplina de Medicina Legal do Departamento de Medicina Legal, Ética Médica, Medicina Social e do Trabalho da Faculdade de Medicina da Universidade de São Paulo.

2. Perito Criminal do Núcleo de Toxicologia Forense do Instituto Médico Legal de São Paulo, SP.

3. Prof. Livre-docente da Disciplina de Medicina Legal da Faculdade de Medicina da Universidade de São Paulo e de Medicina Legal e Bioética da Faculdade de Medicina da Santa Casa de São Paulo, Laboratório de Investigação Médica - LIM-HCFMUSP.

Endereço para correspondência: Rua Teodoro Sampaio, 115 - CEP 05405-000 - São Paulo, SP. E-mail: vileyton@yahoo.com
} 
LEYTON et al. Uso de anfetamínicos por motoristas profissionais brasileiros: aspectos gerais.

dos motoristas de caminhão haviam feito uso de anfetamínicos associado ou não à cocaína e canabinóides (maconha).

Este trabalho objetiva contribuir com informações a respeito dos anfetamínicos, bem como as implicações do seu uso por condutores de veículos, sobretudo os de carga.

\section{Anfetamínicos}

\subsection{Generalidades}

Considera-se anfetamínicos, o grupo de substâncias composto pela anfetamina e seus derivados $^{14}$. A anfetamina foi sintetizada em $1887 \mathrm{e}$ introduzida no mercado por volta de 1930 no tratamento da congestão nasal. Durante a $2^{\mathrm{a}}$ Guerra Mundial, os anfetamínicos foram largamente utilizados para manter os combatentes em alerta. Rapidamente, se tornaram populares em diversos segmentos da sociedade, tanto no tratamento da obesidade, da narcolepsia, do Transtorno do Déficit de Atenção/Hiperatividade (TDA/H) como agente de dopagem ou como droga de abuso'.

Os anfetamínicos são potentes estimulantes do sistema nervoso central (SNC), apresentando marcada influência sobre as atividades psíquicas e psicomotoras, alto potencial de abuso, propiciando o desenvolvimento de farmacodependência e ocorrência de efeitos colaterais que podem se manifestar por alterações cardiovasculares, neurológicas e psiquiátricas, cumulativas com o uso contínuo ${ }^{17}$.

Os medicamentos a base de anfetamínicos mais utilizados são os denominados moderadores do apetite. Possuem em sua composição principalmente fenproporex e anfepramona (dietilpropiona). Estima-se que $60 \%$ da produção mundial de fenproporex é utilizada no Brasil ${ }^{13}$ muitas vezes em formulações ditas "milagrosos emagrecedores 100\% naturais" contendo principalmente fenproporex e anfepramona.

Apesar de sua comercialização estar sujeita às normatizações da Portaria 344 de 12/05/1998 da Vigilância Sanitária, vários medicamentos à base de anfetamínicos podem ser facilmente encontrados e adquiridos em postos de combustíveis ao longo das rodovias sem controle algum.

A Tabela 1 exibe alguns anfetamínicos comercializados no Brasil ${ }^{2,4}$.

Tabela 1 - Alguns anfetamínicos

\begin{tabular}{l|l}
\hline Nomes comerciais & Princípio ativo \\
\hline $\begin{array}{l}\text { Dualid, Inibex, } \\
\text { Hipofagin, Moderine }\end{array}$ & $\begin{array}{l}\text { Anfepramona } \\
\text { (dietilpropiona) }\end{array}$ \\
\hline $\begin{array}{l}\text { Lipomax, Desobesi, } \\
\text { Lipese }\end{array}$ & Fenproporex \\
\hline $\begin{array}{l}\text { Dasten, Absten, } \\
\text { Moderamin, Fagolipo, } \\
\text { Inobesin, Lipese, Diazinil }\end{array}$ & Mazindol \\
\hline
\end{tabular}

\subsection{Toxicidade e efeitos adversos}

Os anfetamínicos são capazes de aumentar a atividade motora, melhorar o humor, inibir o sono e diminuir as sensações de cansaço ou fome. A intensidade de seus efeitos depende da dose utilizada e da personalidade do indivíduo. Doses orais de 10 a $30 \mathrm{mg}$ podem ocasionar euforia, bemestar, melhora da auto-estima e do estado de vigília, aumentando a capacidade física e intelectual. $\mathrm{O}$ raciocínio do usuário parece ser mais rápido e os reflexos motores mais aguçados. O início da ação é dependente da via de administração e os efeitos duram cerca de 6 a 8 horas $^{12}$.

Os anfetamínicos apresentam um alto potencial de abuso, propiciando o desenvolvimento de farmacodependência. A tolerância (necessidade de maiores doses para se obter os mesmos efeitos) aos efeitos subjetivos e anorexígenos é instalada rapidamente; o usuário pode apresentar disforia, confusão mental, depressão, fadiga e mostrar-se agitado, desconfiado, ansioso, sendo que alguns tornam-se hostis e agressivos. Nos casos de overdose, a toxicidade é uma extensão dos efeitos farmacológicos ocorrendo disritmias cardíacas, hipertensão, hipertermia, falência aguda renal, acidose metabólica e coma ${ }^{10,14,15}$.

A Tabela 2 apresenta a relação entre os sinais e 
LEYTON et al. Uso de anfetamínicos por motoristas profissionais brasileiros: aspectos gerais.

sintomas com a severidade da intoxicação provocada pelo uso de anfetamínicos ${ }^{10,18}$.

Tabela 2 - Evolução dos sinais e sintomas devido ao uso de anfetamínicos

\begin{tabular}{l|l}
\hline $\begin{array}{l}\text { Severidade da } \\
\text { intoxicação }\end{array}$ & Sinais e sintomas \\
\hline leve & $\begin{array}{l}\text { abolição da fadiga, loquacidade, } \\
\text { irritabilidade, insônia, tremor, } \\
\text { hiperreflexia, midríase, rubor, } \\
\text { náuseas, vômitos, palidez. }\end{array}$ \\
\hline moderada & $\begin{array}{l}\text { hiperatividade, confusão mental, } \\
\text { hipertensão, taquipnéia, taqui- } \\
\text { cardia, náuseas, vômitos, dores } \\
\text { abdominais e torácicas, cefaléia, } \\
\text { sudorese, elevação da tempera- } \\
\text { tura, impulsividade, comporta- } \\
\text { mento repetitivo, alucinações, } \\
\text { reações de pânico. }\end{array}$ \\
\hline \multirow{5}{*}{ séria } & $\begin{array}{l}\text { delírios, acentuadas hipertensão } \\
\text { e taquicardia, hiperpirexia (acima } \\
\left.\text { de } 40^{\circ} \mathrm{C}\right), \text { convulsão, disritmia } \\
\text { cardíaca, colapso circulatório, } \\
\text { falência renal, acidose metabólica, } \\
\text { coma, morte. }\end{array}$ \\
\hline
\end{tabular}

\subsection{Anfetamínicos e condução veicular}

Estudo feito pelo CEL - Centro de Estudos em Logística da Universidade Federal do Rio de Janeiro aponta uma frota de 1,8 milhão de caminhões em 2001. Desse total, cerca de 900 mil são dirigidos por motoristas autônomos. A média de idade dos caminhões é de 18 anos e $72 \%$ deles têm mais de 11 anos de uso, a maioria sem manutenção adequada. A título de comparação, a idade média da frota de caminhões nos EUA é de 7,2 anos. A combinação de fatores tais como: frota envelhecida e sem manutenção preventiva (pneus, freios, suspensão), policiamento falho, estradas mal conservadas e mal sinalizadas, excesso de velocidade, aliada a motoristas despreparados para enfrentar as dificuldades e imprevistos de extensas jornadas de trabalho a que se obrigam (muitos ficam acordados 20 horas) e que ainda fazem uso de outras drogas, resulta em graves acidentes envolvendo caminhões ${ }^{11}$.

Em 2001, 394.500 veículos automotores (de uma frota de cerca de 32 milhões) envolveram-se em acidentes resultando em 394.596 vítimas, sendo 20.039 fatais ${ }^{7}$.

Segundo o DNER - Departamento Nacional de Estradas de Rodagem, no ano de 2000 , os veículos de passeio envolveram-se em 108.011 acidentes e os caminhões em 50.342. Considerando que os veículos pesados representam apenas $7 \%$ da frota nacional, e que esses dados referem-se tão somente às ocorrências em estradas policiadas, estes dados tornam-se preocupantes. Informes da Polícia Rodoviária Estadual de São Paulo revelam que dois em cada 10 acidentes de trânsito envolvem caminhões ${ }^{5}$.

Frente a esses números é preocupante que os motoristas se vejam estimulados ao uso indiscriminado de substâncias que possam aumentar artificialmente o período de trabalho. Muitos caminhoneiros justificam o uso de "rebites" como uma necessidade. Segundo eles, a prática ocorre para que possam cumprir os horários de entrega das cargas, uma vez que as empresas impõem prazos muito curtos para tal; além disso, o intervalo de tempo entre as viagens é reduzido para compensar o baixo valor do frete (grande número de motoristas viaja ininterruptamente por 15, 20h ou mais). Nas transportadoras esses problemas tendem a ser menores, pois os prazos são um pouco mais realistas e as viagens têm intervalos maiores.

Uma pesquisa realizada pela Faculdade de Saúde Pública da Universidade de São Paulo, com 43 motoristas de caminhão que rodam pelas estradas brasileiras, revelou que $83,3 \%$ dos consultados admitiram que costumam apelar aos anfetamínicos para conseguir se manter acordados ao volante. Com elas, os motoristas conseguem trabalhar até 60 horas semanais contra as $44 \mathrm{~h}$ dos que dirigem nas áreas urbanas e não usam estimulantes. A média de comprimidos consumidos chega a $50 /$ mês para cada motorista ${ }^{19}$.

Segundo relatos desses profissionais, os medicamentos mais utilizados são os moderadores de apetite, vendidos ilegalmente em postos de combustíveis ou restaurantes ao longo das estradas. 
LEYTON et al. Uso de anfetamínicos por motoristas profissionais brasileiros: aspectos gerais.

Dois dos mais populares, Nobese e Lipomax, chegam ilegalmente pelo Paraguai, abastecendo os postos de venda ao custo de $R \$ 10,00$ a cartela com 20 comprimidos. Em média, 3 a 4 comprimidos são ingeridos antes da viagem; alguns caminhoneiros costumam ingerí-los com conhaque, refrigerantes de cola ou café. $O$ efeito de cada comprimido tem a duração de 6 horas, aproximadamente ${ }^{8,20}$.

Depoimentos revelam que a sensação acarretada após o consumo do rebite é de vitalidade, como se o indivíduo acordasse de uma longa noite de sono, tornando o motorista disposto a enfrentar uma longa jornada de trabalho: (...) "seu coração fica acelerado, demorando a voltar ao batimento normal, logo após sente fome". A maioria dos motoristas que fazem uso de rebites são obesos e tem problemas de hipertensão, por isso, antes de fazerem exames médicos periódicos, tomam Lasix com alguns dias de antecedência para não acusarem problemas de pressão e poderem continuar na profissão. (...) "você fica totalmente ligado, a noite passa num instante; quando se usa muito rebite, numa hora está doido, noutra fica parecendo uma barata tonta; às vezes não consegue saber se o farol que vem em sentido contrário está na sua pista ou na outra e é nessa hora que ocorrem os acidentes".

Os relatos ainda chamam atenção pela ocorrência de alucinações: "vi um navio enorme vindo em sentido contrário e tomei um susto; freei a carreta e só depois me dei conta de que era apenas um ônibus"; "confundi sinalizadores de concreto que estavam à beira da pista com um rolo compressor; achei que a máquina vinha em minha direção e quase causei um acidente ao frear a carreta de repente"; "vi vários cavalos na pista; para não atropelar os animais "imaginários" joguei o caminhão para fora da estrada e, por ironia, atropelei um cavalo de verdade que pastava ao longo da pista".

Da análise destes depoimentos pode-se esperar como resultado previsível acidentes envolvendo caminhões uma vez que:

- o uso de anfetamínicos permite que os motoristas cumpram longas horas de viagem mais rapidamente; entretanto, a atenção e concentração ficam prejudicadas;

- quando cessam os efeitos estimulantes, é comum o aparecimento de uma fase depressiva, com fadiga, torpor, inibição mental e uma forte sonolência, alterando a percepção e o tempo de reação do indivíduo;

- os anfetamínicos agem na pupila produzindo midríase, este efeito é prejudicial aos motoristas, pois à noite ficam mais ofuscados pelos faróis dos carros em direção contrária;

- em doses elevadas podem surgir distúrbios como paranóia, reações de pânico e alucinações, levando o indivíduo a frear sem motivo aparente; - a associação etanol-anfetaminas pode levar a um aumento da toxicidade cardíaca e exarcebar os efeitos adversos acarretados em nível cerebrovascular ${ }^{2,10}$.

\section{Recomendações}

Algumas medidas são necessárias para se evitar o uso e abuso de anfetamínicos pelos motoristas, entre as quais: realizar um controle rigoroso da venda destes medicamentos, com maior fiscalização nos postos de gasolina e restaurantes ao longo das estradas; estabelecer limites aceitáveis para as jornadas de trabalho dos motoristas de caminhão, restringindo as horas de viagem por dia; rever os prazos de entrega das cargas pelas empresas transportadoras; adotar medidas para a divulgação de informações sobre os danos à saúde e os riscos envolvidos na utilização indiscriminada dos anfetamínicos.

É interessante também a implantação de programas, por parte das empresas de transporte, que objetivem um ambiente de trabalho livre de drogas com o monitoramento dos seus funcionários por meio de análises toxicológicas à semelhança de empresas que fazem o controle de álcool nos seus trabalhadores.

A implantação dessas medidas poderia reduzir significativamente o número deste tipo de acidentes de trânsito. 
LEYTON, V.; CARVALHO, D. G DE; JESUS, M. G S. DE; MUÑOZ, D.R. Amphetamine use by truck drivers in Brazil: general aspects. Saúde, Ética \& Justiça, 5/7(1-2):32-6, 2000-2002.

Abstract: Various epidemiological studies have been performed to show the relationship between the use of amphetamines and motor vehicle accidents. Truck drivers in Brazil use stimulant drugs, known as "rebites", to reduce fatigue and enhance their performance to achieve dead lines and schedules agreed with the companies. The aim of the present article is to contribute with information about amphetamines and how these psychoactive substances affect the drivers, mainly the truckers.

Keywords: Amphetamines/toxicity. Amphetamines/adverse effects. Automobile driving/statistics \& numeral data.

\section{Referências}

1. Amphetamines. Disponível em: URL: http:// www.streetdrugs.org/amphetamine.htm. Acesso em: 24 out. 2003.

2. Anfetaminas, bolinhas, rebites. Disponível em: URL: http://www.cebrid.epm.br/folhetos/anfetaminas_htm. Acesso em: 11 set. 2003.

3. Couper, F.J.; Pemberton, M.; Jarvis, A.; Hughes, M.; Logan, B.K. Prevalence of drug use in commercial tractor-trailer drivers. J. Forensic Sci., 47(3):562-7, 2002.

4. DEF Interativo 2003/04. Disponível em: URL: http:// www.epuc.com.br/def/. Acesso em: 19 out. 2003.

5. Departamento Nacional de Estradas de Rodagem. Disponível em: URL: http://revistaautoesporte. globo.com/Autoesporte/0,6993,EAD3028671686,00.html. Acesso em: 15 ago. 2003.

6. Del Rio, M.C.; Gomez, J.; Sancho, M.; Alvarez, F.J. Alcohol, illicit drugs and medicinal drugs in fatally injured drivers in Spain between 1991 and 2000. Forensic Sci. Int., 27:63-70, 2002.

7. Denatran - Anuário Estatístico de Acidentes de Trânsito 2001. Disponível em: URL: http:// www.denatran.gov.br/acidentes.htm. Acesso em: 10 set. 2003.

8. Desafio ao tempo e à segurança das estradas. Disponível em: URL: http://www.revistaocarreteiro. com.br/ano2003/Edicao345/rebites.htm. Acesso em: 02 out. 2003.

9. Drummer, O.H.; Gerostamoulos, J.; Batziris, H.; Chu, M.; Caplehorn, J.; Robertson, M.D.; Swann, P. The incidence of drugs in drivers killed in Australian road traffic crashes. Forensic Sci. Int., 134(2-3):154-62, 2003.

10. Ellenhorn, M.J.; Barceloux, D.G. Medical toxicology. New York: Williams \& Wilkins, 1997. p.340-52.

11. Guia-log estatísticas. Disponível em: URL: http:// www.guiadelogistica.com.br/estatistica-transpo.htm. Acesso em: 15 ago. 2003.
12. Hardman, J.G.; Limbird, L.E.; Molinoff, P.B.; Ruddon, R.W.; Gilman, A.G., eds. Goodman \& Gilman's the pharmacological basis of therapeutics. 9. ed. New York: McGraw-Hill Professional,1996. p.219-21.

13. International Narcotic Control. Psychotropic substances: statistics for 1996. United Nations, 1998. p.258.

14. Kalant, $\mathrm{H}$. The pharmacology and toxicology of "ecstasy" (MDMA) and related drugs. C MA J, 2:1657, 2001.

15. Kolanowsky, J. A risk-benefit assessment of antiobesity drugs. Drug Saf., 20(2):119-31, 1999.

16. Logan B.K.; Schwilke, E.W. Drug and alcohol use in fatally injured drivers in Washington State. J. Forensic Sci., 41(3):505-10, 1996.

17. Musshoff, F. Illegal or legitimate use? Precursor compounds to amphetamine and methamphetamine. Drug Metabol. Rev., 32(1):1544, 2000.

18. Oga, S. Fundamentos de toxicologia. 2. ed. São Paulo: Atheneu, 2003.

19. Pesquisa avalia a saúde dos caminhoneiros Disponível em: URL: http://www.usp.br/agenciausp/bols/ 2000/rede624.htm. Acesso em: 15 set. 2003.

20. Rebites. Disponível em: URL: http:// www.minutodotransito.hpg.ig.com.br/ conteudorebite.htm. Acesso em: 14 set. 2003.

21. Shih-Ku, L.; Chao-Hui, L.; Chun-Hung, P.; Wei-Hern, $\mathrm{H}$. Comparison of the prevalence of substance use and psychiatric disorders between government and self-employed commercial drivers. Psychiatry Clin Neurosci., 57(4):425, 2003.

22. Silva, O.A.; Greve, J.M.D.; Yonamine M.; Leyton, V. Drug use by truck drives in Brazil. Drugs: education, prevention and policy, 10(2):135-39, 2003. 